\title{
Ludic markers for player-player observation in location based mobile games
}

[Author copy, cite with permission]

Paula Alavesa, Minna Pakanen, Timo Ojala, Karri Ojala, Kennedy Opoku Asare, Mikko Lehto and Hannu Kukka

Center for Ubiquitous Computing, P.O Box 4500, 90014 University of Oulu, Finland

\section{Abstract}

Background: It can be difficult to capture the subtleties of social behavior during gameplay by using existing commercial location-based mobile games as a research probe since they are not designed to reveal subtleties in player behavior.

Aim: We sought to explore whether players spontaneously search for unknown fellow players and to identify ludic markers in player-player observation when playing a digital location-based mobile game that allows location spoofing in addition to automated locationing.

Method: We used a constructive research approach and created a game specifically designed to allow location spoofing through self-reporting of player locations. We conducted three field trials with eight participants in total. They took part in separate field trials in groups of three, three, and two players. The participants were previously unknown to each other and commenced play at different locations inside the game area.

Results and Conclusions: Qualitative analysis of the gathered video and interview material shows that the players spontaneously searched for unknown fellow players, which confirms earlier research on the topic. Further, behavioral and direct visual markers in the physical environment were reported to be the most significant cues in determining who is a player and who is not.

Keywords: Location-based mobile games, pervasive games, digital games

Abbreviations: Location-Based Mobile Games (LBMGs), Quick Response code (QR code), Assisted Global Positioning System (A-GPS), Uncle Roy All Around You (URAAY), User Interface (UI) 


\section{Introduction}

Location-based mobile games (LBMGs) are a subcategory of pervasive games. These games aim at expanding game elements of traditional gaming (Kasapakis \& Gavalas, 2015; Montola et al., 2009). In location-based games, the game balance and game events are always tied to a physical location, whether by a quick response $(\mathrm{QR})$ code or the coordinates provided by the assisted global positioning system (A-GPS) on a smartphone. The used location coordinates can be set on a map as the spawn spots of Pokémon in Pokémon GO (Niantic Inc., 2016), or they can be in constant motion as in the coordinates of the fellow players in games such as Hitchers or Blowtooth (Drozd et al., 2006; Hegarty et al., 2002). The previous examples use automated locationing to acquire player coordinates. Alternatively, locationing can be based on self-reporting of locations by players. Some classic LBMGs (Benford et al., 2004; Pac Manhattan, n.d.; Montola et al., 2009) have explored the possibilities of using self-reported location data. However, most current LBMGs utilize the built-in A-GPS in smartphones. This is likely due to the ubiquitous availability of GPS service and its integration into current smartphones. Further, early research findings promote the use of automated locationing when available (Benford et al., 2004). In fact, self-reported locationing can be considered as unwanted player behavior in location spoofing, the purposeful manipulation or falsification of location data. In this article, we investigate how incorporating self-reported locationing 
and location spoofing in game mechanics can be leveraged to explore social interactions between players during gameplay. The aim of our research is to provide more detailed descriptions of the indirect and direct cues, i.e., ludic markers (Montola et al., 2009) the players use for player-player observation. As the experimental construct, we use the Here n' There game that is purposefully designed to provide the players a high level of agency in self-reporting their location (Figure 1).

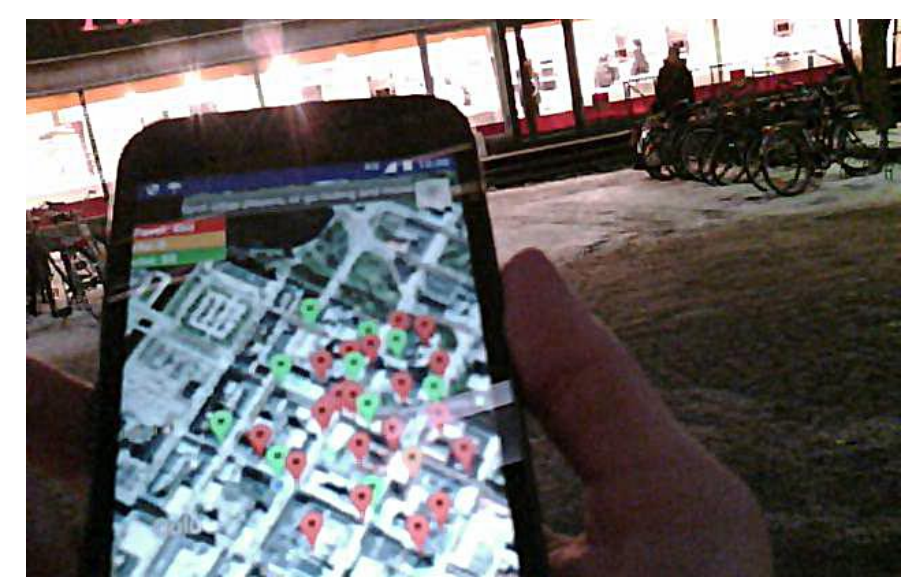

Figure 1. User checking other players' location in Here n' There game UI during a field trial (Map data: @2017 Google).

\section{Background}

Location-based mobile games are a subgenre of pervasive games, where game mechanics are coupled with location data. Many LBMGs utilize databases of fixed locations or pointof-interest (POI) data in the game design. They often tie their game content into specific coordinates, such as Pokémon GO (Niantic Inc., 2016) does with Pokémon and 
Geocaching (O'Hara, 2008) does with caches. This is not always the case, however, and game mechanics of a game that does not rely on a static set of coordinates can be quite complex. For example, game-related locations can be affixed to moving objects, or even to unsuspecting bystanders. For example, in Blowtooth (Kirman et al., 2012) any bystanders who have Bluetooth on their mobile phone are unsuspectingly taking part in the game by carrying "packages."

Games that take place in unpredictable real-life physical environments have to adjust to ever-changing conditions as well as the limitations of the used infrastructure. One solution to this is to take advantage of the environmental ambiguities (Chalmers et al., 2005; Montola et al., 2009). Location data is somewhat ambiguous and inaccurate, despite improvements in the accuracy of automated locationing over the last decade. Creatively utilizing location data in game design requires more than just placing contents in specific coordinates. Location data alternates over time and subsequently has a temporal dimension extending beyond spatial (Lefebvre, 1991). Bill (Chalmers et al., 2005a) is a location-based game where network coverage is used in accordance with the seamful design concept (Chalmers \& Galani, 2004; Weiser, 1994). In the game, players need to shuttle between poor and good network coverage inside the game area. Hence, a known issue of unreliable network connectivity is creatively exploited in the design of game mechanics. Feeding Yoshi (Bell et al., 2006) is a location-based mobile game where the network coverage is used in quite a similar way as in Treasure (Chalmers et al., 2005b). While the seamful designs of previous location-based games have mostly exploited 
aforementioned technical seams, we sought to explore the ambiguous seam between emplacement and displacement. Farman (2011) has defined embodiment as transformation of people and space into place, which in urban spaces is often mediated by smartphones. The complexity of the resulting space can also result in misplacement or displacement, i.e., a sense of being here and there (Farman, 2011). Our design of the Here n' There game seeks to use location data as a tether between the virtual (or digital) and physical game worlds. We also wish to use self-reporting of location data as a game mechanic that provides an incentive for the players to interact with each other.

\section{Self-reported locationing in game design.}

Mobility and automated locationing are unique characteristics of mobile interfaces and their exploitation in the design of contemporary LBMGs is self-evident (Ermi \& Mäyrä, 2005). Today, most, if not all, LBMGs utilize a network assisted global positioning system (A-GPS). Self-reporting of location data has been partly abandoned due to the significant miniaturization of GPS hardware and its seamless integration in smartphones. Early pervasive games using location data required bulky equipment carried around in backpacks (Benford et al., 2006). This bulky form factor together with the inaccuracy of

GPS at the time fueled the interest in exploring the possibilities of location self-reporting as game mechanics. Examples of such games include Uncle Roy All Around You (URAAY) (Benford et al., 2004) and PacManhattan (PacManhattan, n.d.; Montola et al., 2009). URAAY was a classic location-based game where in the first phase players had to 
follow a path leading to Uncle Roy's office using self-reported locations. Benford et al. (2004) concluded that self-reported locationing should only be used as a backup in case automated locationing is not possible. PacManhattan (PacManhattan, n.d.; Montola et al., 2009) is a version of Pacman played on physical city streets. The game uses selfreported locationing on certain nodes on the city map. The justification was that GPS was not adequate in the urban canyons between high-rise buildings in New York. With only self-reported locations on a stylized map, the game worked well for the duration of the short game round of about 10 minutes.

\section{Formation of social groupings in LBMGs.}

Pokémon $G O$ has social implications and that social motivation is a significant factor in engaging players in the gameplay. Some empirical research exists on the social interactions among Pokémon GO players (Paavilainen et al., 2017; Vella et al., 2017). Licoppe and Inada (2006) studied the behavior of LBMG players in MOBI where virtual objects are collected with a mobile phone. The mobile game application serves as a radar featuring a map with a radius of 500 meters. The map represents the environment of the player with her pictogram in the center of the mobile screen surrounded by those of the other players and virtual objects. Players can capture objects within 300 meters of their current location. $M O B I$ was one of the first location-based games to report the surprising effects in player behavior when players are provided with an indirect way of observing each other. Players used their mobile game application to observe other players, though 
it was not an intended goal of gameplay. It has been shown that it is natural for children to come up with games, such as tag or hide and seek, when using digital devices that can be adapted for use in different kinds of games or play (Bekker et al., 2010).

In general, play can be considered as "not serious" activity that has no material interests but abides by rules. It promotes formation of social groupings, where the binding factor is the secrecy and exclusiveness of participating in the play (Huizinga, 1955). This is especially meaningful in pervasive games that take place in a daily living environment (Stenros, 2012). Montola et al. (2009) referred to the items that distinguish gameplay from non-gameplay as "ludic markers." These markers can also tell who is a player and who is not (Montola et al., 2009). Digital location-based games have an element that relates to an older tradition of playing hide and seek, where players observe other players in the field or on a map on a smartphone screen and further invent both direct and indirect ways for this observation. The cues used for this observation then become the ludic markers to identify players.

The conflict that arises from the context of pervasive games can create ethical issues. A situation that is playful for the player is not always so for the bystanders (Montola et al., 2009). As well as being potentially exciting to the players, unexpected encounters with bystanders and other players can become frightening when the parties do not trust each other or share the same implicit rules of street sociability (Lehtonen \& Mäenpää, 1997; de Souza e Silva, 2008; Stenros, 2012). 
In addition to social grouping, the gameplay in LBMGs affects the formation of place. The simplest form of representing space and location proportionally are map applications. Actual space and mapped space are not exclusive separate spaces, as they were during the days of paper maps. The interaction between the physical space and the represented space is constructive and can result in a new realization of space and places for the players. Mapping and the related cultural capital form the basis of our game design. We were further inspired by the balance of emplacement and displacement that describes the complexity of the sensation of being there for an urban dweller who can be connected to more than one physical place via his or her mobile device's interface (Farman, 2011). To the best of our knowledge, no prior LBMGs exist that would allow players to be situated physically or as a projection anywhere in the game area, as well as simultaneously be displaced at a different location by choice. A recent commercial game, Resources, allows players to add one spoofed or fake location per day by using in-game "drones." This is done to distract other players, and it further shows a creative way of using and incorporating fake locations into gameplay (BITLANTIS, n.d.).

\section{Here 'n There}

We recognized an opportunity for designing a game where the core game mechanics are built around the idea of faking, i.e., spoofing the player location as a means to inspire finding other players. We acknowledge that other games with self-reported locationing have already done this to an extent. However, these games have not incorporated both 
automated locationing by smartphones and location self-reporting, to enable "being" in two or more places simultaneously while targeting or trying to avoid an adversary.

We utilized a constructive design research approach (Koskinen et al., 2011) in designing the Here n' There game. The design process was initiated with a thorough review of location-based games and the use of location data in game design. Then, initial concept ideas of gameplay mechanics and user interface (UI) design were iterated. After that, the Here n' There mobile application UI and architecture were implemented.

Location-based mobile games like Pokémon GO (Niantic, 2016), Parallel Kingdom (Parallel Kingdom, n.d.), and Ingress (Niantic, n.d.) use a map as a basis for reporting, displaying, and projecting the game reality. We decided to use a similar map-based approach for creating a game of tag where the players can chase and try to catch each other on a restricted indoor or outdoor arena. The Here n' There game is designed for short, intense gameplay to avoid player fatigue, both psychological and physical. Furthermore, since we were interested in investigating the indirect and direct observation of the other players during gameplay, we supported this in the gameplay design by adding UI elements that reflect the player status. These elements included the leaderboard, which is known to be used in indirect observation of fellow players (Licoppe \& Inada, 2006; Benford, 2006; Alavesa \& Ojala, 2015). Once we had a functional prototype, we conducted playtesting in the field. At the same time, we also inspected the level of accuracy of the locationing inside our game areas and the dynamics of moving between 
the different game modes. This resulted in shortening the time available for creating fake locations and allowing the players to add as many fake location beacons as they liked. We also removed the automatic movement detection from the game design as we realized that there was a need for the players to hide themselves during the games, but no incentive to stay hidden for too long, since they could not receive any points or see other players when hiding.

\section{Gameplay}

The gameplay has similar dynamics to a game of tag or hide and seek, with the distinction of the digital overlay and the possibility for a player to have multiple locations in the digital realm. The players are allowed to add fake locations and become invisible on the game map while moving in the physical world. Other players can see the location beacons only when a player is immobile. Players are naturally also able to observe each other in the physical environment. The built-in point system rewards players for close proximity to fellow players. However, for the purpose of this trial we planned our setup as such that the researchers would not directly suggest the players to find each other.

During the game, a player is either in visible or hiding mode. When players are hidden, they will not be able to spot other players or gain points. If they choose to come out of hiding, they will have 15 seconds to place fake markers on the game map before their fake locations as well as their automatically reported A-GPS location become visible to fellow players. When players are in the unhidden mode, they can tap fellow players' 
location beacons on the map. For each fake location beacon, they get 1 point, for the AGPS location 10 points. If they are in close proximity $(40 \mathrm{~m})$ to the player they are targeting, they get 20 points for real location and 5 points for a fake location. The purpose of this was to give the players a slight push towards moving inside the game area as well as trying to find each other. The game ends after an agreed time for gameplay has passed, in our field trials this was 10 minutes per one game round.

After login, the game application shows all game elements on a single map-based view (Figure 2). Players can use the mobile game application to indirectly observe each other. The leaderboard has the player names color-coded to correspond to the color of the players' location beacons. The leaderboard is updated in real-time to reflect the status of the game. If the game map appears empty of other than one's own location beacons, it should be apparent to the player that the other players are hiding. 


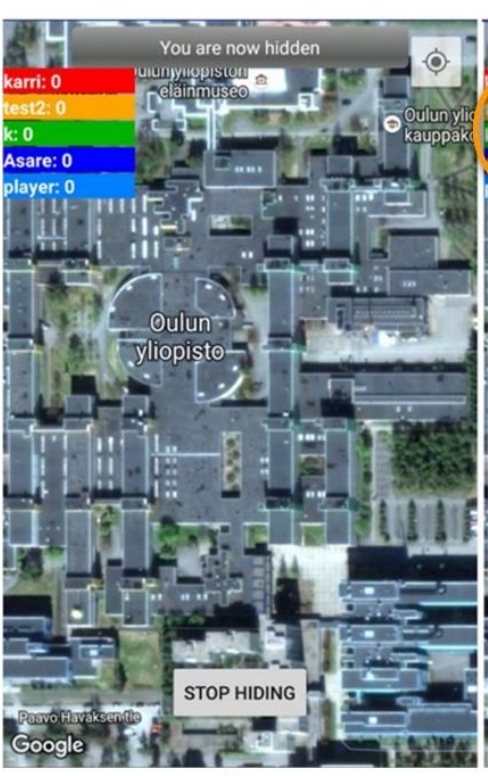

A

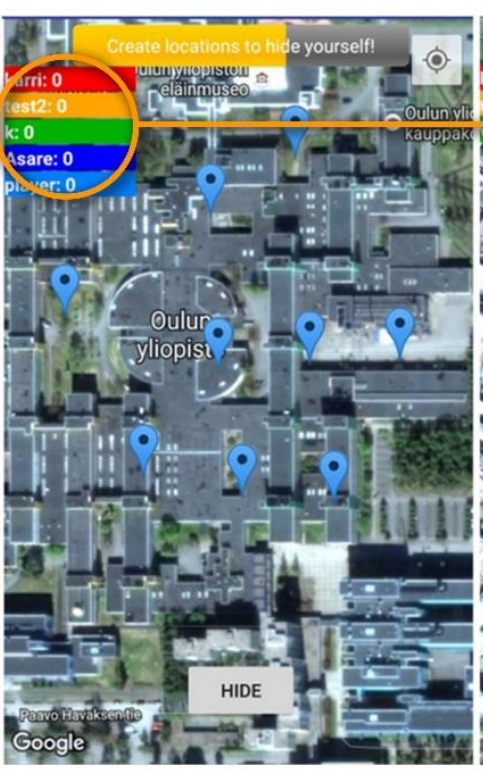

B

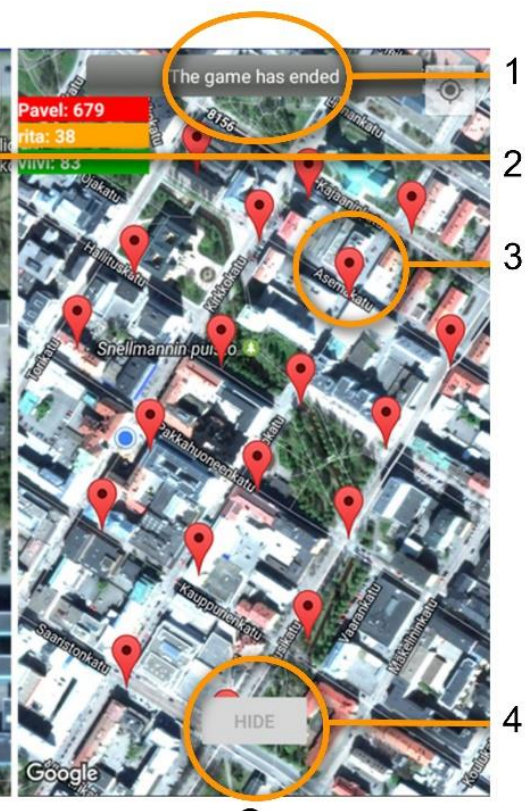

C

Figure 2. Features of the game UI. A, the player is hiding, B, the player has stopped hiding and is placing fake locations, and $\mathrm{C}$, the player can get points by tapping other players' location beacons if they are not hiding. Details in the UI include: 1) game status notifications, 2) real-time leaderboard, 3) player beacon, and 4) hide options and notifications on scoring (Map data: @2017 Google).

\section{Field Trial Setup}

We ran three field trials, one in a restricted indoor location (university campus) and two in an urban downtown area. The research environment was uncontrolled, yet in Table 1 we list some aspects where the different locations clearly varied. Each trial had two game rounds of ten minutes. 
Table 1. Comparison of the two sites for Here n' There field trials.

\begin{tabular}{ccc} 
Conditions & Campus & City \\
\hline Temperature & $22^{\circ} \mathrm{C}$ & $-5^{\circ} \mathrm{C}$ \\
\hline Lighting & Indoor lighting & Street lights \\
\hline Area & $0.01 \mathrm{~km}^{2}$ & $1.1 \mathrm{~km}^{2}$ \\
\hline Game rounds & $2 \times 10 \mathrm{~min}$ & $4 \times 10 \mathrm{~min}$ \\
\hline Players & 3 & 3 in I and 2 in II \\
\hline
\end{tabular}

\section{Devices and data collection.}

We provided players with Motorola MotoG 3rd Generation phones with 4G data plan SIM cards to be used in the game trials. The game server logged the used data of the game application as well as player locations during the field trials. Each participant was further given a small $(55 \mathrm{~mm} \times 20 \mathrm{~mm} \times 20 \mathrm{~mm})$ camcorder to be worn on their chest. Camcorders recorded the complete game events (e.g., Figure $\mathbf{1}$ is a snapshot from a captured video).

\section{Participants.}

We kept the number of participants per game intentionally low, three participants per trial, to be able to observe them and to analyze their movement and interaction with each 
other during gameplay. Furthermore, this was the minimum setup for a situation where one player was hidden, but two others could be gaining points for each other's locations, which would show on the real-time leaderboard for the hidden player and entice him/her to come out of hiding. Participants were recruited through an open call via university mailing lists. They were asked to answer a pre-questionnaire upon sign-up, a few days before each game trial. The questionnaires included a consent form and questions to assess the participants' motivation and features that might affect their ability to track other players on the field such as color blindness, face blindness, familiarity with the game area, or environmental spatial ability. For the latter, we used the self-report measure of environmental spatial ability developed by Hegarty et al. (2002). Our objective was to recruit players who would not know each other, for this reason we also avoided having participants in the same field of occupation or studies on a same game round.

Due to a last-minute cancellation by one participant in the third field trial, we eventually had eight participants in total with ages between $22-41(M=30 ; S D=7,6)$, four males and four females. Participants' fields of study varied from logopedics to electrical engineering. The participants in the same game round did not know each other beforehand. None of the players reported having color or face blindness. They showed some individual variability in their environmental spatial ability, but nothing that can be considered a disability. Each participant was equally awarded with a movie ticket worth approximately 10 euros after a field trial was over. 
In field research, researcher-subject interaction can affect the behavior and thus bias the results. The charisma of the guide is known to affect the user experience (Brown et al., 2011; Klein \& Myers, 1999; Yule et al., 2015). We aimed at minimizing the playerresearcher interaction by having minimal communication with the participants before setting them off to play the game. For this reason, we printed out leaflets that had written instructions, screenshots of the game app, and a map of the game area. Each player was deployed from a different location at the same time when the game was initiated by the researchers. During each trial we ran one ten-minute practice round followed by two rounds that were the main focus for our analysis.

\section{Data Analysis}

We viewed the video material carefully to assess the players' involvement in gameplay. For further analysis, we mainly used the audio track that contained the players' comments on gameplay. Immediately after each game round, we conducted structured interviews, focused on how the players observed each other during gameplay. Interviews were recorded (and video recorded for data integrity) and later transcribed for coding, as was the audio track of the video material from gameplay. The coding schema was built on initial eclectic coding of both the video and gathered data. Table 2 displays the three main coding categories and the 12 subcategories. 
Table 2. The categories or the coding schema for summarizing and coding the gathered data on player-player observation.

\begin{tabular}{c|c} 
Category & Subcategory \\
\hline $\begin{array}{c}\text { Physical ludic } \\
\text { marker (direct cue) }\end{array}$ & Behavior, Scanning the crowd, camera, ID sticker on the phone \\
\hline $\begin{array}{c}\text { Digital ludic marker } \\
\text { (indirect cue) }\end{array}$ & $\begin{array}{c}\text { Players showing on the app, Moving location beacon, Clustered location beacons, } \\
\text { Recollection of the location beacons, Leaderboard or notification }\end{array}$ \\
\hline $\begin{array}{c}\text { Hybrid ludic } \\
\text { marker (comparison } \\
\text { of indirect and } \\
\text { direct cues) }\end{array}$ & $\begin{array}{c}\text { Moving location beacon and player movement on the field, Comparing locations } \\
\text { on the map to where people were situated, Location beacon close to one's own } \\
\text { location }\end{array}$ \\
\hline
\end{tabular}

The main categories are summarized as follows:

- Physical ludic markers: These are mainly direct cues for player observation, such as using elements of the surrounding people or environment to observe other players or suspect where they might be, an example quote: "There was a person there who was looking at his phone and kept checking his surroundings and, yes well, was acting like I did while I was playing the game" (Player ID33, City trial 2).

- Digital ludic markers: These are mainly indirect cues for player observation, such as when a player sees in the game app something that is used to suspect another player, an example quote: "Well there in the beginning of the game I saw that there were many red dots of which one moved a bit towards a known landmark" (Player ID33, City trial 2). These cues relate to how the game mediates player-player interaction.

- Hybrid ludic markers: This refers to the players using both indirect and direct cues for player observation. For instance, a situation where the player compares the information from the physical world to the information given by the game app, an example quote from the material: "I looked from the phone who was moving and then tried to check from the people who was also moving close by" (Player ID29, Campus 
trial). As these markers combine both digital and physical hybrid markers they can be called hybrid ludic markers.

Because we constructed a new coding schema, we found it necessary to do a thorough agreement testing (Bakeman \& Quera, 2011) on both the schema (Table 2) and the results (Table 3). We did two stages of agreement testing and parallel coding. First stage agreement testing was conducted for refining the schema as well as for identifying and sorting prevalence-problems. In the second stage, the schema went through a point-bypoint agreement based on Cohen's kappa (Bakeman \& Quera, 2011; Fleiss et al., 2013) with a third observer, who was new to the gathered data. On the three categories of 46 items the number of observed agreements was $42(91.1 \%)$ and the strength of agreement considered to be "very good." The weighed kappa was 0.779 and assessed this way the strength of agreement was considered "good."

Table 3. The frequencies of events on the method of player observation.

\begin{tabular}{|c|c|c|c|}
\hline & $\begin{array}{c}\text { Physical ludic marker } \\
\text { (direct cue) }\end{array}$ & $\begin{array}{c}\text { Digital ludic marker (indirect } \\
\text { cue) }\end{array}$ & $\begin{array}{c}\text { Hybrid ludic markers } \\
\text { (comparison of indirect and } \\
\text { direct cues) }\end{array}$ \\
\hline & Behavior (16) & Players showing on the app (6) & $\begin{array}{l}\text { Moving location beacon and } \\
\text { player movement on the field ( } 2 \text { ) }\end{array}$ \\
\hline & $\begin{array}{l}\text { Scanning the crowd } \\
\text { (4) }\end{array}$ & Moving location beacon (2) & $\begin{array}{l}\text { Comparing locations on the map } \\
\text { to where people were situated ( } 2 \text { ) }\end{array}$ \\
\hline & Camera (5) & Clustered location beacons (2) & $\begin{array}{l}\text { Location beacon close to one's } \\
\text { own location (1) }\end{array}$ \\
\hline & Phone ID sticker (1) & $\begin{array}{l}\text { Recollection of location } \\
\text { beacons ( } 2 \text { ) }\end{array}$ & \\
\hline & & Leaderboard or notification (3) & \\
\hline In total & 26 & 15 & 5 \\
\hline
\end{tabular}


Over the 12 subcategories, we observed $36(78 \%)$ from the 46 items and the number of agreements expected by chance was 6.7 (15\%). The weighed kappa was 0.755 hence the strength of agreement was considered to be "good." Most of the disagreement between the two observers was on how to differentiate between Group behavior ("Scanning the crowd") and Individual behavior ("Behavior").

\section{Results}

The results of the coding method for player-player observation can be found in Table 3 . The players used mainly physical ludic markers (direct cues) from surrounding people or potential players to deduct who was a player. The most important was bystanders' or suspected players' behavior. We did not differentiate between or have expectations for the sensory modalities of the cues, yet all the coded items in the material point to the use of visual cues in observation. An interesting event took place during the first game round where players admitted in the interview to observing a bystander and how they held their phones. The other player followed the person for a moment only to notice that this person lifted his phone to his ear and had in fact been tapping a phone number. "Yes, I did look if someone was walking with a mobile phone in their hand [gestures tapping a phone screen] and wondered if there was one." "Yes, more than once, and one I followed and then he/she put the cell phone on his/her ear." (Between players ID 30 and ID 28, Campus trial.) 
Although players used the presence of the camera to observe others at first, they soon realized that it was not that easy to spot other players: "First I tried to spot the cameras, of course. It is quite visible, well yours is hidden, actually both of your cameras are well hidden, but mine was visible. But then I guess you did not actually spot it, although I felt like you would" (Player ID29, Campus trial). The effect of the chest-worn camera is therefore diminished in the results as the players could already see during the practice round or early in the game that the camera is difficult to spot.

\section{Player Motivation}

In order to have insight on whether the players sought each other without outside influence we coded the player motivation using the same method as previously described. For these results the number of observed agreement was 15 out of 18 and the number of agreements expected by chance 3.6, with kappa value 0.792 , weighed kappa value 0.792 , and "good" strength of agreement. Victory was stated as a goal by many players (3) as well as doing better or beating others in the game (5). One answer, when enquired what the participant thought is the purpose of the game, sums the motivation of the players well: "Of course, strategize, beat the competition and gather as much points as possible, find out where he/she really is located" (Player ID30, Campus trial). Finding other players was stated to be an equal motivator for the players, on par with victory: "Yes, there was kind of joy from recognizing the other person, but at the same time fear for being caught yourself. Like, if that person now recognizes me, the points will go for them. It will be too 
easy for them to snap the points and know where one is going" (Player ID29, Campus trial).

\section{Player Activity}

Player activity, in regard to what means the players used to collect points, varied during each game round (Figure 3).

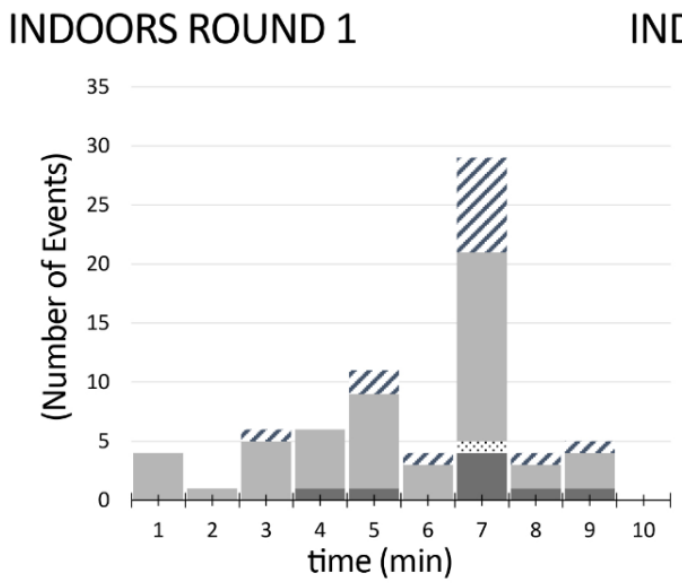

INDOORS ROUND 2

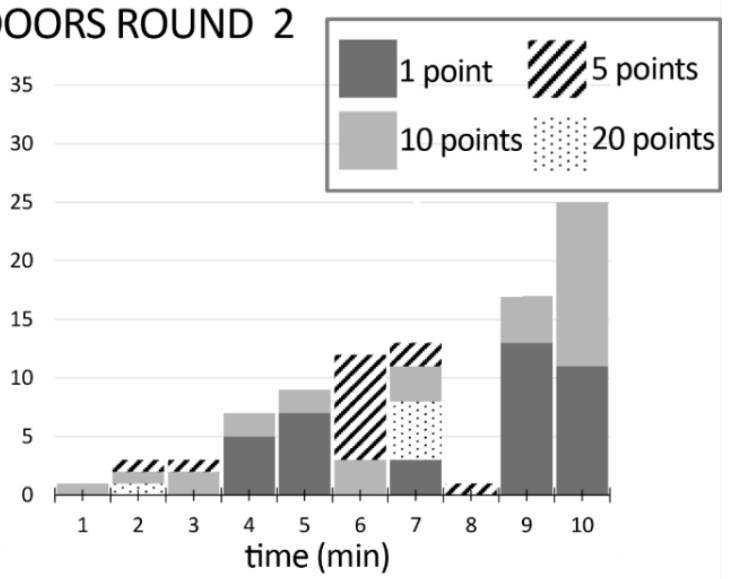

CITY TRIAL 1 ROUND 1

CITY TRIAL 2 ROUND 2

60

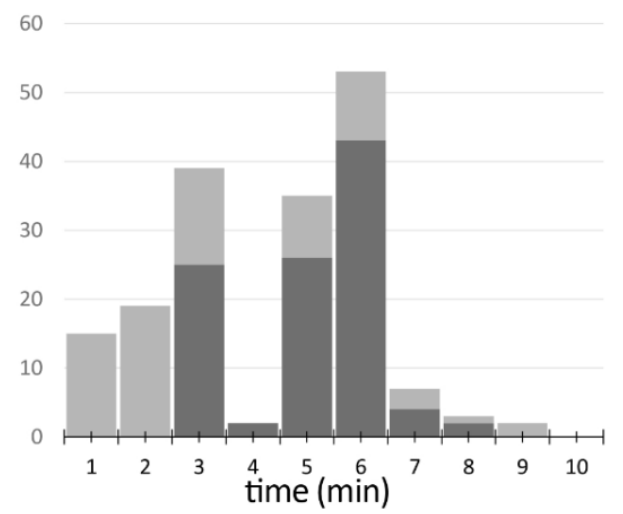

Figure 3. Player activity and how the players collected points during each game round minute by minute. 
It is apparent that in a smaller, more restricted indoor game area, the players gained more points due to unintentionally closer physical proximity with other players. However, during the same time period in the larger game area there was more game-related activity in the form of tapping the location beacons on the game application. For the second city game, where we had only two players, there was no significant activity on scoring amongst the players. However, the video material shows that the players were actively playing the game and during the interview they stated trying to find each other: "Well there in the beginning of the game I saw that there were many red dots of which one moved a bit towards [a known landmark]. I clicked that, and it was bull's eye, then on the next round I saw one dot there at that same locations. Clicked it, bull's eye again. So, I thought this guy must be at the [known landmark]. So, I began to move towards him and I saw him come towards me from that direction" (Player ID 33, City trial 2). However, their scoring activity was low as they collected only 21 points. We saw no reason for graphical presentation of those numbers.

\section{Other Observations}

The scoring system appeared balanced enough, including the $40 \mathrm{~m}$ maximum distance for "targeting" another player. Allowing players to also gain points from fake and fake close by locations proved to work well on all game trials. The scoring system further gave a target for observing the player actions. When moving from the smaller indoor game arena to the outdoor arena, we expected the gameplay to improve. Instead, players had a harder 
time tracking each other. In the first trial on the small indoor arena, the three players recognized each other in five out of the six potential player recognition pairings. In the two city games, the players recognized another player only in two out of the eight potential instances. The taps on fake locations dominating player scoring (Figure 3) illustrate the difficulty of locating other players on the larger game arena.

\section{Discussion}

The formation of social groupings is intrinsic in play (Huizinga, 1955). In addition, social interaction has been found to be a key motivator for players of location-based games such as Geocaching (O'Hara, 2008). If a game does not provide a direct path for social interaction, people try to find each other, even when it is not the actual goal of the game (Licoppe \& Inada, 2006). In addition, it seems that Pokémon GO (Niantic, 2016) has created an affordance for using map-based mobile applications to find things, in our case people. We avoided suggesting that the participants should use their game application for anything specific, yet one player stated before the first game round: "So this is like Pokémon GO, but instead of Pokémon we try to find other people" (Player ID30, Campus trial). Through constructive research we were able to study player-player and playerbystander observation with the kind of detail we would have been unable to achieve by studying Pokémon $G O$ players. Pokémon $G O$ players would have little possibility for indirect player-player observation using the digital ludic markers since the game map does not show locations of the fellow players, neither is there a leaderboard. 
Without obvious ludic markers for identifying fellow players, the interaction between participants can become more exciting (Montola et al., 2009). Our game provided mediation for recognizing fellow players but they themselves still relied mainly on physical ludic cues, including behavioral markers for identification. We noticed that players spontaneously sought other players out. Conversely, our findings suggest that the physical ludic markers from the physical environment dominate how players observe each other in the field (Tables 3 and 4), especially the behavior of the bystanders and how they use and hold their mobile phone. The fake and real locations of players were the digital ludic markers for player-player observation, but they were mostly used to complement observations from the physical game arena.

Even with a simple game such as Here n' There, using the physical environment as a game arena brings complexity to the gameplay and allows players to use their imagination in a way a more situated game would not allow. In our experiment, the physical ludic marker in player-player observation dominated. However, the actual gameplay possibly requires both physical and digital ludic markers for more versatile gameplay and to make the gameplay interesting and fun. Hence, we do not recommend emphasizing onedirectional observation methods in game design.

Our findings show that a game such as Here n' There can be used to entice people to look up from their mobile phones and notice each other. However, this design also poses ethical considerations as the game creates an incentive for stalking bystanders in addition 
to fellow players. Despite anonymity, the players and bystanders acknowledge being observed (Lehtonen \& Mäenpää, 1997; de Souza e Silva, 2008). Prior research also shows that the game can add incentive for player-player observation (Licoppe \& Inada, 2006: Montola et al., 2009). We observed similar incentive for player-bystander observation. Keen player-bystander observation has the potential for being interpreted as disturbing by someone who does not share the same sense of playfulness or trust. Many LBMGs such as Pokémon GO, or Geocaching keep the digital ludic markers for player-player observation out of the game design to provide anonymity for the players (O'Hara, 2008; Niantic, 2016). We noticed that physical ludic markers are more important when observing fellow players, so the lack of digital ludic markers is not necessarily enough to anonymize the players, although it makes them more difficult to track.

\section{Limitations and Future Work}

We introduced into the gameplay some direct cues the players used, such as the ID sticker on the phone and the camera. However, even when they are deducted from the results, the use of direct cues was still more prevalent. Also, the players stated not using the introduced cues once they figured out that they are not that obvious.

We believe our approach of allowing players to fake their location increases freedom of movement. Players can strategize by using the displacement of locations in the physical city streets as well as on the game map. Players can experience the feeling of displacement when playing a location-based or mixed reality game (Alavesa et al., 2017; Benford \& 
Giannachi, 2011). Although in our game this displacement might be at the level of the player location and not the player experience, it would be an interesting target for future research to adapt the Here n' There game design and our field trial setup to research the displacement and its value to game experience in LBMGs. Furthermore, it would be interesting to explore whether the sensation of displacement would be different if $3 \mathrm{D}$ scenes of the city streets would be used instead of 2D maps. This article only describes the nature of the ludic markers in player-player observation. Future research should provide more detailed guidelines for designing LBMGs for varying levels of playerplayer -observation in addition to elaborating the related privacy considerations.

Our research would benefit from further field trials with a larger number of participants. We, however, aimed at complementing the small sample size by prior mapping of the participants' abilities where relevant to our research aim and by collecting rich material for analysis.

\section{Conclusion}

To explore player-player interactions in pervasive location-based mobile gaming, we designed and implemented a game where location spoofing is an integral part of the game mechanics. We collected research data from three field trials and gained interesting results on how players observed each other. Players used different direct and indirect cues to track their fellow players. Physical ludic markers (direct cues), mainly the behavior of bystanders, were found to be the most important markers for recognizing a fellow player. 
Our results also verified existing knowledge on spontaneous player-player observations in location-based games.

\section{Acknowledgements}

The research has been conducted following the ethical requirements established by Finnish advisory board on research integrity. The gathered material has been handled and informed consent from the participants was obtained.

\section{Declaration of Conflict of Interests}

The Authors declare that there is no conflict of interest with respect to the authoring and publication of this article.

\section{Funding}

This work has been supported by the Open Innovation Platforms spearhead project (A70202) and the Open City Model as Open Innovation Platform project (A71143) funded by the ERDF and the City of Oulu under the Six City Strategy program, and the COMBAT project (293389) funded by the Strategic Research Council at the Academy of Finland.

\section{References}

Alavesa, P., Pakanen, M., Kukka, H., Pouke, M., \& Ojala, T. (2017). Anarchy or Order on the Streets: Review Based Characterization of Location Based Mobile Games. 
In Proceedings of the Annual Symposium on Computer-Human Interaction in Play (pp. 101-113). ACM. https://doi.org/10.1145/3116595.3116614

Alavesa, P., \& Ojala, T. (2015). Street art gangs: location based hybrid reality game. In Proceedings of the 14th International Conference on Mobile and Ubiquitous Multimedia (pp. 64-74). Linz, Austria: ACM.

https://doi.org/10.1145/2836041.2836047

Android Developers. (n.d.). Best Practices for User Interface. Retrieved from https://developer.android.com/training/best-ui.html

Bakeman, R., \& Quera, V. (2011). Sequential analysis and observational methods for the behavioral sciences. Cambridge University Press.

Bekker, T., Sturm, J., \& Eggen, B. (2010). Designing playful interactions for social interaction and physical play. Personal and Ubiquitous Computing, 14(5), 385396. https://doi.org/10.1007/s00779-009-0264-1

Bell, M., Chalmers, M., Barkhuus, L., Hall, M., Sherwood, S., Tennent, P., ... Hampshire, A. (2006). Interweaving mobile games with everyday life. In Proceedings of the SIGCHI Conference on Human Factors in Computing Systems (pp. 417-426). Montreal, Quebec, Canada: ACM.

https://doi.org/10.1145/1124772.1124835

Benford, S., \& Giannachi, G. (2011). Performing Mixed Reality. The MIT Press. 
Benford, S., Crabtree, A., Flintham, M., Drozd, A., Anastasi, R., Paxton, M., ... RowFarr, J. (2006). Can you see me now? ACM Trans. Comput.-Hum. Interact., 13(1), 100-133. https://doi.org/10.1145/1143518.1143522

Benford, S., Seager, W., Flintham, M., Anastasi, R., Rowland, D., Humble, J., ... Sutton, J. (2004). The Error of Our Ways: The Experience of Self-Reported Position in a Location-Based Game. In N. Davies, E. Mynatt, \& I. Siio (Eds.), UbiComp 2004: Ubiquitous Computing (Vol. 3205, pp. 70-87). Springer Berlin Heidelberg. Retrieved from http://dx.doi.org/10.1007/978-3-540-30119-6_5

BITLANTIS. (n.d.). Home - RESOURCES GAME - Offizielle Website. Retrieved August 17, 2017, from http://www.resources-game.ch/en/

Brown, B., Reeves, S., \& Sherwood, S. (2011). Into the wild: challenges and opportunities for field trial methods. In Proceedings of the SIGCHI Conference on Human Factors in Computing Systems (pp. 1657-1666). ACM. https://doi.org/10.1145/1978942.1979185

Chalmers, M., Barkhuus, L., Bell, M., Brown, B., Hall, M., Sherwood, S., \& Tennent, P. (2005b). Gaming on the edge: Using seams in pervasive games. In Proc. Pervasive, PerGames workshop.

Chalmers, M., Bell, M., Brown, B., Hall, M., Sherwood, S., \& Tennent, P. (2005a). Gaming on the edge: using seams in ubicomp games. In Proceedings of the 2005 ACM SIGCHI International Conference on Advances in computer entertainment 
technology (pp. 306-309). Valencia, Spain: ACM.

https://doi.org/10.1145/1178477.1178533

Chalmers, M., \& Galani, A. (2004). Seamful interweaving: heterogeneity in the theory and design of interactive systems. In Proceedings of the 5th conference on Designing interactive systems: processes, practices, methods, and techniques (pp. 243-252). ACM. https://doi.org/10.1145/1013115.1013149

Drozd, A., Benford, S., Tandavanitj, N., Wright, M., \& Chamberlain, A. (2006). Hitchers: designing for cellular positioning. In International Conference on Ubiquitous Computing (pp. 279-296). Springer. https://doi.org/10.1007/11853565_17

Ermi, L., \& Mäyrä, F. (2005). Player-centred game design: Experiences in using scenario study to inform mobile game design. Game Studies, 5(1), 1-10.

Farman, J. (2011). Mapping and Representations of Space. In Mobile Interface Theory: Embodied Space and Locative Media (1st ed., pp. 35-55). Routledge.

Fleiss, J. L., Levin, B., \& Paik, M. C. (2013). Statistical methods for rates and proportions. John Wiley \& Sons.

Hegarty, M., Richardson, A. E., Montello, D. R., Lovelace, K., \& Subbiah, I. (2002). Development of a self-report measure of environmental spatial ability. Intelligence, 30(5), 425-447. https://doi.org/10.1016/S0160-2896(02)00116-2 Huizinga, J. (1955). Homo Ludens: A Study of the Play Element in Culture. London, United Kingdom: Routledge \& Kegan Paul. 
Kasapakis, V., \& Gavalas, D. (2015). Pervasive gaming: Status, trends and design principles. Journal of Network and Computer Applications, 55, 213-236. https://doi.org/10.1016/j.jnca.2015.05.009

Kirman, B., Linehan, C., \& Lawson, S. (2012). Blowtooth: a provocative pervasive game for smuggling virtual drugs through real airport security. Personal and Ubiquitous Computing, 16(6), 767-775. https://doi.org/10.1007/s00779-0110423-Z

Klein, H. K., \& Myers, M. D. (1999). A set of principles for conducting and evaluating interpretive field studies in information systems. MIS Quarterly, 67-93. https://doi.org/10.2307/249410

Koskinen, I., Zimmerman, J., Binder, T., Redstrom, J., \& Wensveen, S. (2011). Design research through practice: From the lab, field, and showroom. Elsevier.

Lefebvre, H. (1991). The production of space (Vol. 142). Oxford Blackwell.

Lehtonen, T.-K., \& Mäenpää, P. (1997). Shopping in the east centre mall. In The shopping experience (Vol. 1, pp. 136-165). SAGE.

Licoppe, C., \& Inada, Y. (2006). Emergent Uses of a Multiplayer Location-aware Mobile Game: the Interactional Consequences of Mediated Encounters. Mobilities, 1(1), 39-61. https://doi.org/10.1080/17450100500489221

Montola, M., Stenros, J., \& Waern, A. (2009). Pervasive games: theory and design. Morgan Kaufmann Publishers Inc. 
Niantic. (2016). Pokémon GO. Niantic, Inc. Retrieved August 29, 2017, from https://play.google.com/store/apps/details?id=com.nianticlabs.pokemongo

Niantic Labs. (n.d.). Ingress. Retrieved August 12, 2015, from https://www.ingress.com/

O’Hara, K. (2008). Understanding geocaching practices and motivations. In Proceedings of the SIGCHI Conference on Human Factors in Computing Systems (pp. 1177-1186). Florence, Italy: ACM. https://doi.org/10.1145/1357054.1357239

Paavilainen, J., Korhonen, H., Alha, K., Stenros, J., Koskinen, E., \& Mayra, F. (2017). The Pokemon GO Experience: A Location-Based Augmented Reality Mobile Game Goes Mainstream. In Proceedings of the 2017 CHI Conference on Human Factors in Computing Systems (pp. 2493-2498). Denver, Colorado, USA: ACM. https://doi.org/10.1145/3025453.3025871

Pac Manhattan. (n.d.). . Retrieved January 11, 2017, from http://www.pacmanhattan.com/

Parallel Kingdom. (n.d.). Parallel Kingdom. Retrieved August 25, 2016, from http://www.facebook.com/parallelkingdom de Souza e Silva, A. (2008). Hybrid reality and location-based gaming: Redefining mobility and game spaces in urban environments. Simulation \& Gaming.

Stenros, J. (2012). In defence of a magic circle: the social and mental boundaries of play. In Proceedings of DiGRA Nordic 2012 Conference: Local and Global- 
Games in Culture and Society (Vol. 2012).

https://doi.org/10.26503/todigra.v1i2.10

Vella, K., Johnson, D., Cheng, V. W. S., Davenport, T., Mitchell, J., Klarkowski, M., \& Phillips, C. (2017). A Sense of Belonging: Pokémon GO and Social Connectedness. Games and Culture, 1555412017719973. https://doi.org/10.1177/1555412017719973

Weiser, M. (1994). Building invisible interfaces. Keynote talk. Proc. ACM UIST.

Yule, D., MacKay, B., \& Reilly, D. (2015). Operation Citadel: Exploring the Role of Docents in Mixed Reality. In Proceedings of the 2015 Annual Symposium on Computer-Human Interaction in Play (pp. 285-294). London, United Kingdom: ACM. https://doi.org/10.1145/2793107.2793135 